\title{
UPPERMANTLE ANISOTROPY AND THE OCEANIC LITHOSPHERE
}

\author{
Don L. Anderson and J. Regan \\ Seismological Laboratory, California Institute of Technology, Pasadena, California, 91125
}

\begin{abstract}
Rayleigh wave and Love wave dispersion data for oceanic paths cannot be satisfied by an isotropic uppermantle, and it is incorrect to invert these two datasets independently for separate isotropic structures. Available phase and group velocity data are inverted for oceanic structure as a function of age taking into account anelastic dispersion, sphericity, and anisotropy. The resulting models are quite different from previous results which ignore the above effects and the extra parameters involved in proper anisotropic inversion.

The models have a high-velocity nearly isotropic layer at the top of the mantle that thickens with age, and an anisotropic lowvelocity zone with an age-dependent anisotropy. The LID, or seismic lithosphere, reaches a maximum thickness of $50 \mathrm{~km}$ which is about one-half the thickness obtained in previous isotropic or pseudo-isotropic inversions. The seismic lithosphere therefore may be comparable in thickness to the elastic or flexural lithosphere, raising the possibility that both are controlled by effects other than temperature, stress and time, such as mineralogy, crystal orientation or partial melting. The velocities in the low-velocity zone are higher than inferred by previous surface wave studies.
\end{abstract}

\section{Introduction}

There have been many surface wave studies of the structure of the oceanic uppermantle. The general agreement between the various studies and the calculation of resolving kernels might lead one to expect that we are in the model refinement stage and that no major surprises are in store. There is general agreement, for example, that the seismic lithosphere, or LID, is about $100 \mathrm{~km}$ thick in old ocean basins and that, at all ages, it is much thicker than the flexural lithosphere. Although there are formalisms for estimating uniqueness and resolving power of a given set of geophysical data these are applied only after decisions and assumptions have already been made about model parameterization and what class of models is considered appropriate. This paper shows that the self-consistent inversion of oceanic surface wave data gives results which are drastically different from previous results. In this paper we are concerned mainly with LID thickness and its variation with age. This is part of a more general study which will be presented elsewhere.

The thickness of the lithosphere and the variation of thickness with age and tectonic setting are central issues in the theory of plate tectonics. The rheological properties of the uppermantle depend, among other things, on temperature; the effects of temperature and thermal cooling have dominated discussions of the properties and evolution of the lithosphere. If temperature is the only parameter, the thickness of the elastic lithosphere, defined as the depth at which the relaxation time is smaller than the duration of the load for a given deviatoric stress, will not be the same as the thickness of the seismic high velocity layer, or LID. Strength and creep resistance also depend on crystal structure and orientation, stress, duration of load and partial melting. If the base of the lithosphere is controlled by a change in crystal structure, or the onset of partial melting, then the lithosphere may be the same as the LID.

From the study of seamount loading we know that the elastic lithosphere thickens rapidly to a thickness of about $30 \mathrm{~km}$ at 40

Copyright 1983 by the American Geophysical Union.

Paper number $3 \mathrm{~L} 1247$.

$0094-8276 / 83 / 003 \mathrm{~L}-1247 \$ 03.00$
My (Watts et al., 1980). This is much thinner than current estimates of the thickness of the seismic lithosphere (e.g. Schlue and Knopoff, 1977). In a homogeneous mantle the effective lithospheric thickness is much smaller for high stress, long duration loads than for low stress, short duration seismic waves (Anderson and Minster, 1980). On the other hand, if the uppermantle is chemically layered or if phase changes are important, the change in mineralogy may be as significant as the change in temperature in controlling the rheological and seismic properties. In general, Love wave and Rayleigh wave dispersion data over oceanic paths cannot be satisfied by the same isotropic structure. Previous estimates of the thickness of the seismic lithosphere have either ignored anisotropy or have treated it in a way that is not even approximately correct. Some recent studies have assumed that $\mathrm{SH}$ and $\mathrm{SV}$ are different but that $\mathrm{SH}, \mathrm{SV}$, and $\mathrm{P}$ are individually isotropic. This is not a valid procedure. In most inversions, gravity and sphericity of the Earth have been ignored or treated approximately. Finally, the effect of anelastic dispersion is often ignored. In the present study we take all of these factors into consideration and treat anisotropy in a self-consistent manner. For the class of models considered, the LID thickness is comparable to the thickness of the elastic lithosphere.

If the mantle is anisotropic, the use of Rayleigh waves alone is of limited usefulness in the determination of mantle structure because of the trade-off between anisotropy and structure (Anderson, 1966; Anderson and Dziewonski, 1981). Love waves provide an additional constraint. In the present study we use published phase and group velocity data for fundamental mode Love waves and Rayleigh waves. We assume that these data are an adequate azimuthal average so that we can treat the oceanic uppermantle as a transversely isotropic solid with five elastic constants. The azimuthal variation of long-period surface waves appears to be small (Forsyth, 1975).

Fundamental mode Love and Rayleigh wave data are not sufficient to obtain all five elastic constants and density in the various regions of the uppermantle. We start with the density and VPH/VSH, VPV/VSV, and $\eta$ ratios from PREM (Dziewonski and Anderson, 1981), which reduces the number of parameters to 2 for each region. We also adopt the PREM Q values and assume that $Q$ does not vary with frequency, geographic position or direction.

\section{Procedure}

Fundamental mode surface wave data have limited resolving power. Most short-period surface wave data can be fit with a simple model involving a water layer, crust, LID, LVZ, and halfspace. If the crustal model is given, the main parameters are thickness and velocity of the LID and velocity in the LVZ. If the velocities in the crust and deeper mantle are assumed known from other studies and the density is held constant, there are still five parameters even for an isotropic model. For an anisotropic model, with five elastic constants in each layer, the parameters number 11. Modelling of regional dispersion data therefore requires other constraints or assumptions.

We start with dispersion data for average ocean, the most complete regional dataset and one that differs only slightly from the average Earth dataset. The longer period surface wave data were fitted by adjusting the shear velocity in the LVZ, keeping VSV/VSH, VPV/VPH, VSV/VPV, $\eta$ and $\rho$ fixed at the PREM values. This corresponds to a single parameter inversion. The shorter period data, 20-60 seconds, are used to determine the thickness and velocity in the LID. The water depth, sediment 


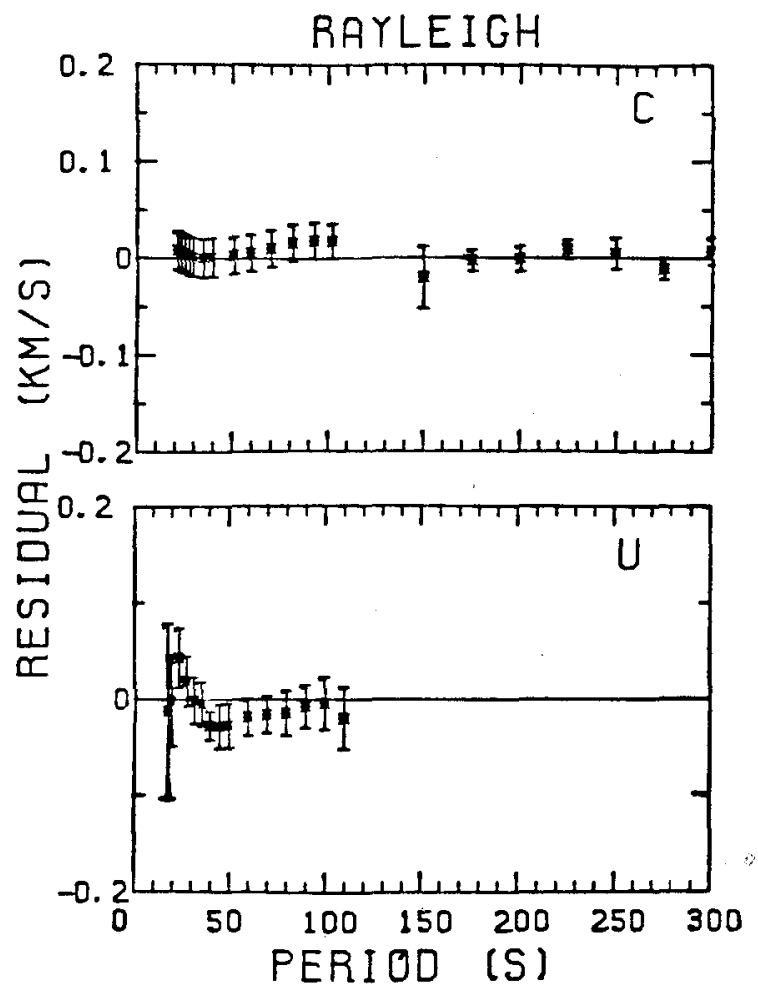

Figure 1. Rayleigh wave phase and group velocity residuals for the average ocean model. A positive residual indicates the model is faster than the data.

parameters and starting crustal values were picked to be appropriate for average age ocean. The sub-Moho layer is assigned velocities based on refraction data. Once a modified PREM structure is found for average age ocean, the data for successively older and younger ocean are fitted by making minimal modifications to PREM-AVERAGE OCEAN.

The procedure is:

1. Assign water depth and crustal structure as appropriate for given age ocean.

2. Adjust thickness and velocity of crust and LID to satisfy short-period data.

3 . If necessary, adjust velocity of $\mathrm{LVZ}$, keeping all ratios constant.

4. If necessary, adjust gradient of velocity, keeping all ratios constant.

5. If necessary, decouple VSH/VSV, keeping VSH/VPH, VSH/VPV constant.

6. If necessary, decouple VSH/VPH and VSV/VPV.

7. If necessary, vary velocity between 220 and $400 \mathrm{~km}$.

In general the dataset for each age province could be satisfied by making minimal changes in the previous model. Of all the oceanic regions considered, only the youngest ocean required perturbations below $220 \mathrm{~km}$. Young ocean has velocities less than PREM to a depth of $400 \mathrm{~km}$.

The data are from Mitchell and Yu (1980), Forsyth (1975), Kanamori (1970), and Wielandt and Knopoff (1982) and include Love and Rayleigh wave phase and group velocity in the period range 20 to 300 seconds. Most of the data are for periods shorter than 100 seconds. These data have all been inverted before, but this is the first time that sphericity, gravity, anelastic dispersion, and anisotropy have all been considered together. In some cases the Love and Rayleigh wave data have been inverted separately in an attempt to account for anisotropy, but this procedure is not valid (Anderson, 1966; Kirkwood, 1978). Rayleigh wave dispersion is also very sensitive to the P-wave anisotropy (Dziewonski and Anderson, 1981; Anderson and Dziewonski, 1982). In olivine-rich rocks the P-wave anisotropy is as pronounced as the S-wave anisotropy (Christensen and Smewing, 1981). Models which assume $\mathrm{P}$-wave isotropy and S-wave anisotropy (Schlue and Knopoff, 1978) are similar to completely isotropic models.

The final fits for average age ocean are shown in Figures 1 and 2. The model is shown in Figure 3. The mantle LID is 35 $\mathrm{km}$ thick. This is much thinner than previous isotropic or pseudo-isotropic inversions and is comparable to the elastic thickness found from flexural studies (Watts et al., 1980). A similar result, i.e. thin LID, was inferred from long-range refraction measurements in the western Pacific (Nagumo et al., 1981). It is interesting that the separation of the earthquakes in the double Wadati-Benioff zone in Japan (Hasegawa et al., 1978) and the thermally reset thickness of the lithosphere upon passing over a hotspot (Detrick and Crough, 1978) are also about this thickness.

The Average Ocean model was then modified to satisfy the dispersion data for younger and older ocean. The models of the four regionalized provinces are given in Table 1 . The thickness of the mantle LID, for the parameterization and assumptions stated, increases with age from 20 kilometers in the province less than $20 \mathrm{My}$ in age to $50 \mathrm{~km}$ in the province greater than $100 \mathrm{My}$ in age. These thicknesses are also much less than previously thought (Yu and Mitchell, 1979, Schlue and Knopoff, 1977). For example, Schlue and Knopoff (1977) obtain average LID thicknesses of 100 to $131 \mathrm{~km}$ in the older parts of the Pacific basin. Their LVZ velocities are also much lower than ours (e.g. $\mathrm{VSV}=4.06, \mathrm{VSH}=4.22 \mathrm{~km} / \mathrm{sec}$ ). The LID velocity increases with age in the youngest two provinces. Older lithosphere is slightly anisotropic with horizontal velocities faster than vertical velocities. The shallow velocities decrease beyond 50 million years. The dispersion data for older ocean can also be fit by increasing crustal thickness and water depth. However, by using observed average values for old ocean the velocity decrease seems necessary. The gradients of $\mathrm{SH}$ and $\mathrm{PV}$ velocity in the $\mathrm{LVZ}$ increase with age as do the mean $\mathrm{SH}, \mathrm{PH}$, and PV velocities. The mean $\eta$ value and gradient decrease with age in the LVZ.

The variations of LID thickness, with and without crust, are

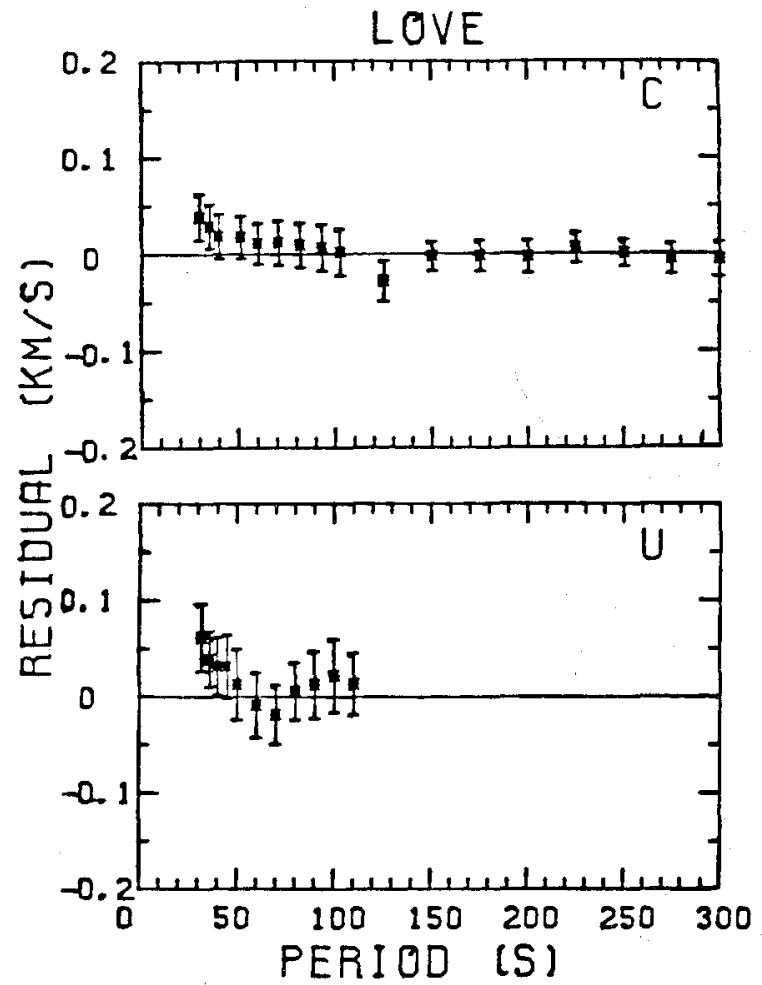

Figure 2. Love wave phase and group velocity residuals for the average ocean model. 
shown in Figure 4. Also shown are estimates of the thickness of the elastic or flexural lithosphere from Watts et al. (1980).

In common with almost all geophysical problems the models we present are not unique. The purpose of this paper, in fact, is to show that a self-consistent anisotropic inversion of oceanic dispersion data gives models which are distinctly different from previously published results. Different parameterizations or assumptions would lead to different models. We have chosen to use a PREM-type modular parameterization and anisotropic parameters from PREM to facilitate comparison of our models with the average Earth. This parameterization also allows direct comparison with the results of Schlue and Knopoff (1977). These authors discuss in some detail the tradeoffs between LID thickness and velocities in the LID and LVZ.

Resolving and tradeoff kernels for anisotropic structures will be presented elsewhere (Nataf and Anderson, in preparation). Calculations of uniqueness and resolving power, however, are useful only if the assumptions behind the modelling are correct. The neglect of anelastic dispersion and anisotropy, for example, results in erroneous structures (Anderson and Hart, 1978; Anderson and Dziewonski, 1982) even though the structure appears to be well resolved using elastic, isotropic resolution kernels (e.g., Jordan and Anderson, 1974; Yu and Mitchell, 1979). In a particularly dramatic example Anderson and Dziewonski (1982) showed that anisotropic models that satisfy both Rayleigh and Love wave data bear little resemblance to models based on Rayleigh wave data alone or on separate isotropic inversion of Love and Rayleigh wave data. Mantle surface wave data, $T>100 \mathrm{sec}$, does not require the presence of a $\mathrm{LVZ}$ as commonly thought. It is the short-period data that require the presence of a LID. A more detailed discussion of the present results will appear in a separate publication.

\section{Conclusions}

Published Rayleigh and Love wave phase and group velocity data have been inverted taking into account sphericity, anelastic dispersion, and transverse isotropy. For a PREM-type modular parameterization, the thickness of the high velocity mantle LID varies in thickness from $\approx 30 \mathrm{~km}$ for young ocean $(20-50 \mathrm{My})$ to $\approx 50 \mathrm{~km}$ for old ocean. These are much less than previous estimates based on isotropic inversion of similar data. This LID thickness is comparable to the elastic or flexural thickness found

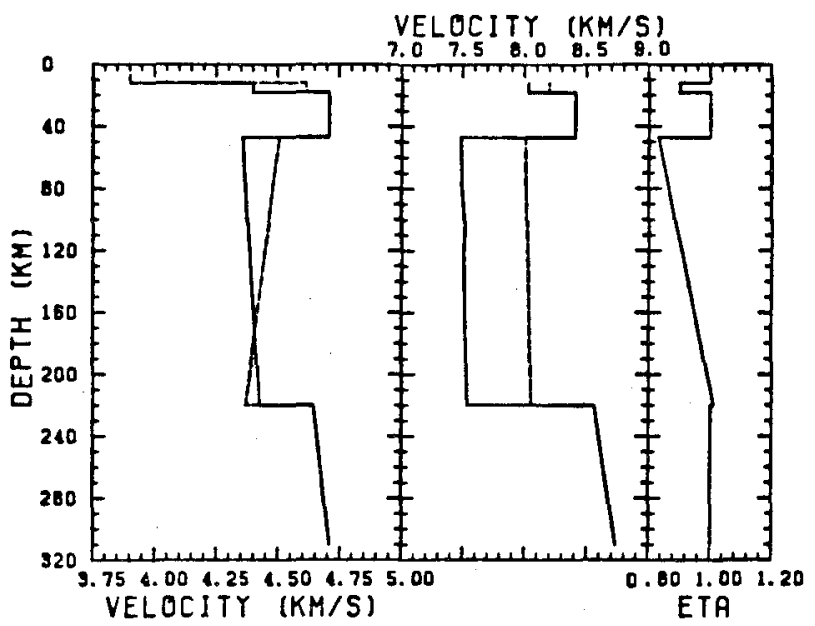

Figure 3. Velocity structure for the average age ocean. From right to left the profiles represent $\eta$ (e.g. Dziewonski and Anderson, 1981), horizontal $\mathrm{P}$ velocity (dashed), vertical $\mathrm{P}$ velocity (solid), horizontal S velocity (dashed), vertical S velocity (solid). Structure below $220 \mathrm{~km}$ is the same as PREM (Dziewonski and Anderson, 1981). Reference period is 1 second.
Table 1. Uppermantle velocities $(\mathrm{km} / \mathrm{sec})$ for each oceanic age province. Thicknesses $(\mathbf{H})$ are in $\mathbf{k m}$. Reference period is $1 \mathrm{sec}$.

\begin{tabular}{|c|c|c|c|c|c|c|c|c|c|c|}
\hline & \multirow{2}{*}{\multicolumn{2}{|c|}{$\begin{array}{l}\text { Water and } \\
\text { Sediments }\end{array}$}} & \multicolumn{2}{|c|}{ Crust } & \multicolumn{2}{|c|}{ LID } & \multicolumn{2}{|c|}{$\mathrm{LVZ}$} & \multirow[b]{2}{*}{220} & \multirow[b]{2}{*}{400} \\
\hline & & & 1 & 2 & 1 & 2 & top & bottom & & \\
\hline \multicolumn{11}{|c|}{$0-20 \mathrm{My}$} \\
\hline $\mathbf{H}$ & 3.45 & 0.02 & 1.51 & 4.64 & 6.00 & 14. & & & & \\
\hline VPV & 1.52 & 1.65 & 5.21 & 6.80 & 8.02 & 8.21 & 7.67 & 7.57 & 8.47 & 8.82 \\
\hline VPH & 1.52 & 1.65 & 5.21 & 6.80 & 8.19 & 8.21 & 7.90 & 7.77 & 8.47 & 8.82 \\
\hline VSV & 0.0 & 1.00 & 3.03 & 3.90 & 4.40 & 4.60 & 4.20 & 4.31 & 4.60 & 4.72 \\
\hline VSH & 0.0 & 1.00 & 3.03 & 3.90 & 4.61 & 4.60 & 4.45 & 4.28 & 4.60 & 4.72 \\
\hline$\eta$ & 1.00 & 1.00 & 1.00 & 1.00 & 0.90 & 1.00 & 0.92 & 1.00 & 1.00 & 1.00 \\
\hline
\end{tabular}

$20-50 \mathrm{M}$

$\begin{array}{ccccccccccc}\text { H } & 4.67 & 0.13 & 1.58 & 5.15 & 6 & 24 & & & & \\ \text { VPV } & 1.52 & 1.65 & 5.21 & 6.80 & 8.02 & 8.42 & 7.77 & 7.59 & 8.47 & 8.82 \\ \text { VPH } & 1.52 & 1.65 & 5.21 & 6.80 & 8.19 & 8.42 & 7.88 & 7.77 & 8.47 & 8.82 \\ \text { VSV } & 0.00 & 1.00 & 3.03 & 3.90 & 4.40 & 4.72 & 4.28 & 4.32 & 4.60 & 4.72 \\ \text { VSH } & 0.00 & 1.00 & 3.03 & 3.90 & 4.61 & 4.72 & 4.39 & 4.29 & 4.60 & 4.72 \\ \eta & 1.00 & 1.00 & 1.00 & 1.00 & 0.90 & 1.00 & 0.93 & 1.00 & 1.00 & 1.00\end{array}$

$50-100 \mathrm{My}$

$\begin{array}{clrllllllll}\text { H } & 5.40 & .23 & 1.60 & 5.19 & 6 & 34 & & & & \\ \text { VPV } & 1.52 & 1.65 & 5.07 & 6.70 & 8.02 & 8.39 & 8.04 & 7.46 & 8.56 & 8.91 \\ \text { VPH } & 1.52 & 1.65 & 5.07 & 6.70 & 8.19 & 8.48 & 8.15 & 8.03 & 8.56 & 8.91 \\ \text { VSV } & 0.0 & 1.00 & 2.96 & 3.84 & 4.40 & 4.70 & 4.43 & 4.25 & 4.64 & 4.77 \\ \text { VSH } & 0.0 & 1.00 & 2.96 & 3.84 & 4.61 & 4.75 & 4.58 & 4.43 & 4.64 & 4.77 \\ \eta & 1.00 & 1.00 & 1.00 & 1.00 & 0.90 & 1.00 & 0.83 & 0.96 & 1.00 & 1.00\end{array}$

$>100 \mathrm{My}$

\begin{tabular}{cllllllllll} 
H & 5.75 & .30 & 1.6 & 5.19 & 6 & 44 & & & & \\
VPV & 1.52 & 1.65 & 5.01 & 6.63 & 8.02 & 8.27 & 8.12 & 7.66 & 8.56 & 8.91 \\
VPH & 1.52 & 1.65 & 5.01 & 6.63 & 8.10 & 8.31 & 8.12 & 8.03 & 8.56 & 8.91 \\
VSV & 0.0 & 1.00 & 2.93 & 3.80 & 4.40 & 4.63 & 4.48 & 4.36 & 4.64 & 4.77 \\
VSH & 0.0 & 1.00 & 2.93 & 3.80 & 4.61 & 4.66 & 4.56 & 4.31 & 4.64 & 4.77 \\
$\eta$ & 1.00 & 1.00 & 1.00 & 1.00 & 0.90 & 1.00 & 0.87 & 0.97 & 1.00 & 1.00 \\
$\mathbf{Q}_{\mu}$ & $\infty$ & 600 & 600 & 600 & 600 & 600 & 80 & 80 & 143 & 143 \\
\hline
\end{tabular}

Age of oceanic lithosphere, (M.Y.)

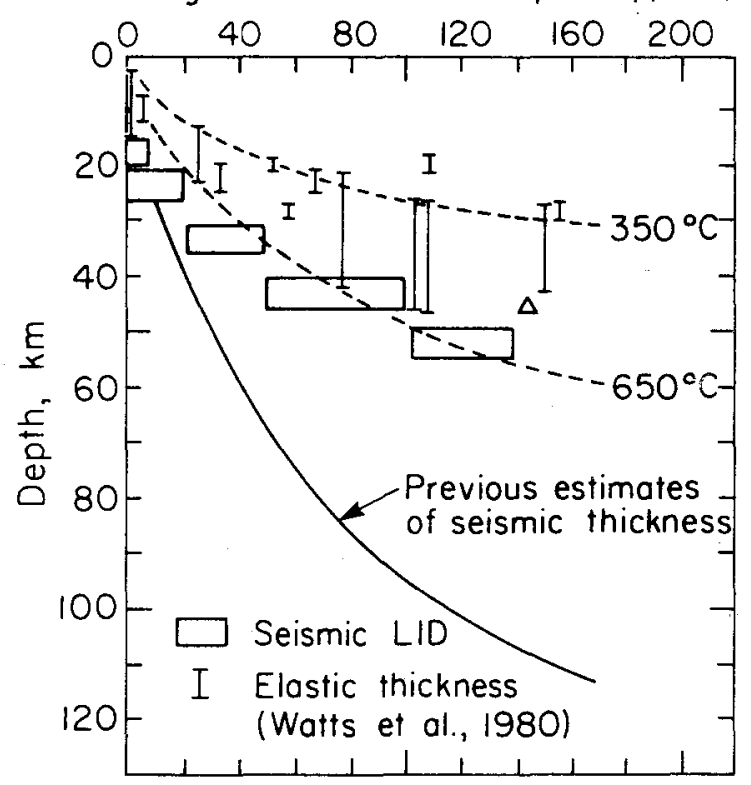

Figure 4. The thickness of the seismic lithosphere as determined in this study. The upper edge of the open boxes gives the thickness of the LID only, the lower edge gives the thickness of the LID plus the crust. The elastic thickness and the isotherms are from Watts et al. (1980). 
from studies of seamount loading and flexure at trenches. This suggests that the thickness of the lithosphere may be controlled by mineralogy, composition, or crystal orientation rather than temperature alone. The low seismic velocities under the East Pacific Rise extend to $400 \mathrm{~km}$, in agreement with Wielandt and Knopoff (1982), Grand and Helmberger (1983), and Walck (1982). Our models have nearly isotropic LIDs and anisotropic LVZs, in agreement with Schlue and Knopoff (1977).

Acknowledgments. We thank Adam Dziewonski for use of a program, Jeff Given for his assistance, and Don Forsyth for helpful discussions. This research was supported by National Science Foundation grant number EAR811-5236 and National Aeronautics and Space Administration grant number NSG-7610. Contribution number 3895, Division of Geological and Planetary Sciences, California Institute of Technology, Pasadena, California 91125.

\section{References}

Anderson, Don L., Recent evidence concerning the structure and composition of the Earth's mantle, Physics and Chemistry of the Earth, v. 6., 1-131, 1966.

Anderson, Don L., Dziewonski, A. M., Upper mantle anisotropy: Evidence from free oscillations, Geophys. $J . R$. astron. Soc., 69, 383-404, 1982.

Anderson, Don L., Hart, R., An Earth model based on free oscillations and body waves, J. Geophys. Res., 81, 1461-1475, 1978.

Anderson, Don L., Minster, B., Seismic velocity, attenuation, and rheology of the mantle: in Source Mechanism and Earthquake Prediction, C. J. Allegre (Ed), Centre National de la recherche scientifique, Paris, 13-22, 1980

Christensen, N. I., Smewing, J. O., Geology and seismic structure of the northern section of the Oman ophiolite, J. Geophys. Res., 86, 2545-2555, 1981.

Detrick, R. S., Crough, S. T., Island subsidence, hot spots, and lithosphere thinning, J. Geophys. Res., 83, 1236-1244, 1978.

Dziewonski, A. M., Anderson, Don L., Preliminary reference Earth model, Phys. Earth Planet. Inter., 25, 297-336, 1981.

Forsyth, D. W., The early structural evolution and anisotropy of the oceanic upper mantle, Geophys. $J . R$. astron. Soc., 43, 103-162, 1975.

Grand, S., D. V. Helmberger, Upper mantle shear structure of North America (in press)

Hasegawa, A., Umino, N., Takagi, A., Double planed structure of the deep seismic zone in the northeastern Japan Arc, Tectonophysics, 47, 43-58, 1978.

Jordan, T., Anderson, Don. L., Earth structure from free oscillations and travel times, Geophys. J. R. astron. Soc., 36, 411, 1974.

Kanamori, H., Velocity and Q of the mantle waves, Phys. Earth Planet. Inter., 2, 259-275, 1970.

Kirkwood, S., The significance of isotropic inversion of anisotropic surface-wave dispersion, Geophys. J. R. astron. Soc., 55, 131-142, 1978.

Mitchell, B. J., Yu, G., Surface wave dispersion, regionalized velocity models and anisotropy of the Pacific crust and upper mantle, Geophys. J. R. astron. Soc., 63, 497-514, 1980.

Nagumo, S., Ouchi, T., Kasahara, J., Koresawa, S., Tomada, Y., Kobayashi, K., Furumoto, A. S., Odegard, M. E., Sutton, G. H., Sub-Moho seismic profile of the Maricena Basin; ocean bottom seismograph long range explosion experiment, Earth Planet. Sci. Lett., 53, 93-102, 1981.

Schlue, J. W., Knopoff, L., Shear-wave polarization anisotropy in the Pacific Basin, Geophys. J. R. astron. Soc., 49, 145-165, 1977.

Schlue, J. W., Knopoff, L., Inversion of surface-wave phase velocities for an anisotropic structure, Geophys. J. R. astron. Soc., 54, 697-702, 1978.

Walck, M., Models of upper mantle compressional velocity under a spreading center, EOS, 63, 1036, 1982.

Watts, A., Bodine, J. H., Steckler, M. S., Observations of flexure and the state of stress in the oceanic lithosphere, J. Geophys. Res., B, $85,6369-6376,1980$.

Wielandt, R., Knopoff, L., Dispersion of very long period Rayleigh waves along the East Pacific Rise: evidence for S-wave velocity anomalies to $450 \mathrm{~km}$ depth, J. Geophys. Res., 87, BIO, 8631-8641, 1982.

Yu, G., Mitchell, B. J., Regionalized shear velocity models of the Pacific upper mantle from observed Love and Rayleigh wave dispersion, Geophys. J. R. astron. Soc., 57, 311-341, 1979.

(Received May 24, 1983;

accepted July $28,1983$. ) 